\title{
Triazoloacridone C-1305 impairs XBP1 splicing by acting as a potential IRE1a endoribonuclease inhibitor
}

\author{
Sylwia Bartoszewska1* , Jarosław Króliczewski ${ }^{2}$, David K. Crossman ${ }^{3}$, Aneta Pogorzelska ${ }^{4}$, Maciej Bagiński ${ }^{5}$, \\ James F. Collawn ${ }^{6}$ and Rafal Bartoszewski ${ }^{2^{*} \text { (D) }}$
}

${ }^{*}$ Correspondence:

sylwiabart@gumed.edu.pl;

rafalbar@gumed.edu.pl

${ }^{1}$ Department of Inorganic

Chemistry, Medical University

of Gdansk, Hallera 107,

80-416 Gdańsk, Poland

2 Department of Biology and Pharmaceutical Botany,

Medical University of Gdansk, Hallera 107, 80-416 Gdańsk,

Poland

Full list of author information is available at the end of the article

\begin{abstract}
Inositol requiring enzyme 1 alpha (IRE1a) is one of three signaling sensors in the unfolding protein response (UPR) that alleviates endoplasmic reticulum (ER) stress in cells and functions to promote cell survival. During conditions of irrevocable stress, proapoptotic gene expression is induced to promote cell death. One of the three signaling stressors, IRE1 a is an serine/threonine-protein kinase/endoribonuclease (RNase) that promotes nonconventional splicing of XBP1 mRNA that is translated to spliced XBP1 (XBP1s), an active prosurvival transcription factor. Interestingly, elevated IRE1 a and XBP1s are both associated with poor cancer survival and drug resistance. In this study, we used next-generation sequencing analyses to demonstrate that triazoloacridone $\mathrm{C}-1305$, a microtubule stabilizing agent that also has topoisomerase II inhibitory activity, dramatically decreases XBP1s mRNA levels and protein production during ER stress conditions, suggesting that C-1305 does this by decreasing IRE1 a's endonuclease activity.
\end{abstract}

Keywords: XBP1s, UPR, ER stress, IRE1a

\section{Introduction}

During tumor development and progression, transformed cells adapt to increased demands on protein and lipid production that are needed for rapid proliferation [1] by enhancing endoplasmic reticulum (ER) function and expansion. To accomplish this, cancer cells take advantage of the adaptive multifunctional signaling pathway called the unfolded protein response (UPR) [1]. The normal function of this pathway is to protect cells against the accumulation of unfolded or misfolded proteins in ER. The UPR does this by activating three ER transmembrane sensors: inositol-requiring protein 1 alpha (IRE1 $\alpha$ encoded by ERN1), protein kinase RNA-like ER kinase (PERK) and activating transcription factor 6 (ATF6) [2]. The function of the UPR is to promote cell survival and restore proper ER function, or alternatively during irrevocable stress, to trigger cell death when cellular homeostasis cannot be restored [3]. Interestingly, cancer cells avoid 
this UPR transition from prosurvival to apoptosis, and therefore strategies that inhibit the prosurvival pathways have become an attractive target for novel anticancer therapies.

Although the all three UPR sensors provide appealing therapeutic candidates, IRE1 $\alpha$ activity has been a major focus because it promotes a protumoral phenotype in several cancers and furthermore, elevated levels of IRE1 $\alpha$ are associated with poor cancer prognosis (reviewed in $[4,5]$ ). IRE1 $\alpha$ is ubiquitously expressed and displays both serine/ threonine kinase and endoribonuclease (RNase) activities. Activation of IRE1 $\alpha$ 's RNAse activity requires trans-auto phosphorylation and subsequent oligomerization of IRE1 $\alpha$

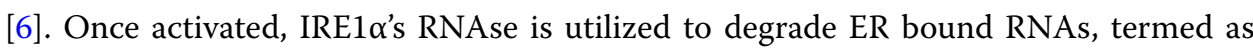
regulated IRE1 $\alpha$-dependent decay (RIDD). A second important function is to remove a 26-base intron from X-box binding protein 1 (XBP1) mRNA in an unconventional splicing reaction that produces a highly active spliced XBP1 (XBP1s) transcription factor [7-12].

XBP1s's function is to enhance the expression of ER-resident chaperones and genes involved in ER associated protein degradation (ERAD) [13] as well as ER expansion [11].

Given that dysregulation of IRE $\alpha$ and XBP1s levels are associated with poor cancer patient survival and drug resistance [14-19] and IRE1's kinase and endoribonuclease activities are required for generating XBP1s, IRE1 $\alpha$ has become an attractive therapeutic targets for novel anticancer therapies. Although numerous small molecules that inhibit IRE1 $\alpha$ activity has been developed, their use in cancer therapy remains limited $[4,5]$, and therefore the search for new drug candidates that inhibit IRE1 $\alpha$ activity is clearly needed. In this study, we demonstrate that triazoloacridone C-1305, a microtubule stabilizing agent that also has topoisomerase II inhibitory activity [20,21], efficiently prevents XBP1 splicing, therefore suggesting that C-1305 inhibits IRE1's endoribonuclease activity. Given C-1305's multiple activities, it could be considered as a potential lead compound to include in the development of future cancer therapeutic strategies.

\section{Materials and methods}

\section{Cell lines and culture conditions}

Human bronchial epithelial 16HBE14o-cells were obtained as previously described (Sigma-Aldrich, Catalog no. \#SCC150) [22]. HeLa S3 cells (ATCC CCL-2.2) and human non-small lung carcinoma A549 cells (ATCC CCL-185) were obtained from American Type Culture Collection (ATCC, Manassas, VA, USA). 16HBE14o-cells were cultured in Minimum Essential Modified Eagle's Medium (Invitrogen) with 10\% fetal bovine serum (FBS), while HeLa S3 cells were cultured in Minimum Essential Modified Eagle's Medium (Thermo Fisher Scientific, Waltham, MA, USA) with $2 \mathrm{mM} \mathrm{L-glutamine} \mathrm{(Mil-}$ liporeSigma, Burlington, MA, USA), antibiotics (100 U/ml of penicillin and $100 \mu \mathrm{g} / \mathrm{ml}$ of streptomycin (MilliporeSigma) with 10\% FBS. A549 cells were cultured in RPMI 1640 media supplemented with $10 \% \mathrm{FBS}$ in a humidified incubator at $37{ }^{\circ} \mathrm{C}$ in $5 \% \mathrm{CO}_{2}$. All experiments were conducted at a final confluence of $70-80 \%$.

\section{Chemicals}

5-\{[3-(Dimethylamino)propyl]amino\}-8-hydroxy-6H-[1,2,3]triazolo[4,5,1-de]acridin-6 one $\left(\mathrm{C}_{18} \mathrm{H}_{19} \mathrm{~N}_{5} \mathrm{O}_{2}, \mathrm{M}_{\mathrm{W}}=337.38 \mathrm{~g} / \mathrm{mol}\right)$ (compound C-1305) was synthesized by the Faculty of Chemistry, University of Gdansk, Poland, and verified for purity and identity with 
RP-HPLC, elemental analysis, ${ }^{1} \mathrm{H}$ NMR spectroscopy and HR MS spectrometry as previously described in $[21,23,24]$. The $\mathrm{C}-1305$ chemical formula is provided in Fig. 1a. Two independent batches of $\mathrm{C}-1305$ were tested. $\mathrm{C}-1305$ was stored in the dark at $4{ }^{\circ} \mathrm{C}$. Prior to the experiments, the compound was always freshly dissolved in DMSO as a $3 \mathrm{mM}$ stock solution. DMSO (Catalog no. S-002-D) was purchased from Sigma-Aldrich. The IRE1 activity inhibitor, $4 \mu 8 \mathrm{C}$, was purchased from Sigma-Aldrich (SML0949) and dissolved in DMSO prior to use.

\section{Induction of ER stress and activation of the UPR}

Pharmacological induction of ER stress and activation of the UPR were performed as we previously described [25]. Briefly, cells were treated with the compounds for the time periods specified: tunicamycin $(0.5 \mu \mathrm{g} / \mathrm{mL}$; Sigma, T7765) and thapsigargin $(\mathrm{Tg}, 25 \mathrm{nM}$ Sigma, T9033). Control (CTRL) cells were treated with vehicle CTRL, DMSO $(<0.5 \%$ v/v; Sigma, D2650).

\section{Isolation of RNA}

Total RNA (containing both mRNA and miRNA) was isolated using miRNeasy kit (Qiagen). RNA concentrations were calculated based on the absorbance at $260 \mathrm{~nm}$. RNA samples were stored at $-70^{\circ} \mathrm{C}$ until use.

\section{Next-generation RNA sequencing analyses}

Cells treated with C-1305 or DMSO vehicle (as specified in "Results" section) were used for the RNA isolation and analyses. Following rRNA depletion, the remaining RNA fraction was used for library construction and subjected to 75-bp single-end sequencing on an Illumina NextSeq 500 instrument (San Diego, CA, USA). Sequencing reads were aligned to the Gencode human reference genome assembly (GRCh38 p7 Release 25) using STAR version 2.5.3b [26]. Transcript assembly and estimation of the relative abundance and tests for differential expression were carried out with HTSeq-count version 0.9.1 and DESeq2 for those samples with biological replicates, and with Cufflinks and Cuffdiff for those samples without biological replicates [26-28]. The resulting data were validated with quantitative real-time PCR. The heat map generation and hierarchical clustering were performed with the Morpheus Web server (Morpheus, https://software. broadinstitute.org/morpheus). The Enrichr Web server (https://amp.pharm.mssm.edu/ Enrichr/) [29] was applied to assign the NGS results into the 'Gene Ontology Biological Process' categories with the selection based on a p-value below $\mathrm{p}=0.05$. Furthermore, the analyses were limited to experimentally verified interactions and no extended gene enrichment set analyses were performed.

\section{Measurement of mRNA quantitative Real Time PCR (qRT-PCR)}

We used TaqMan One-Step RT-PCR Master Mix Reagents (Applied Biosystems) as described previously [30] using the manufacturer's protocol (retrotranscription: $15 \mathrm{~min}, 48{ }^{\circ} \mathrm{C}$ ). The relative expressions were calculated using the $2^{-\Delta \Delta \mathrm{Ct}}$ method [31] with the Glyceraldehyde 3-phosphate dehydrogenase (GAPDH-Hs02786624 g1) and (TBP Hs00427620_m1) genes as reference genes for the mRNA. TaqMan probes ids used: HSPA5-Hs00607129_gH, BBC3 (PUMA)-Hs00985031_g1, DDIT3 
a<smiles>CN(C)CCCNc1ccc2nnn3c4ccc(O)cc4c(=O)c1c23</smiles>

b

cellular response to unfolded protein (GO:0034620)

cellular response to starvation (G0:0009267)

regulation of endoplasmic reticulum unfolded protein response (GO:1900101)

chaperone mediated protein folding requiring cofactor (GO:0051085)

cellular response to heat (GO:0034605)

cellular response to topologically incorrect protein (GO:0035967)

c

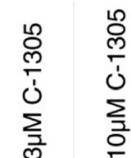

\begin{tabular}{ccl} 
ले & \multicolumn{1}{c}{ Gene } \\
-2.09 & -1.46 & HSPA5
\end{tabular}

$\begin{array}{llll}-2.79 & -3.74 & X B P 1\end{array}$

11.389 .42 BBC3 (PUMA)

4.127 .53 PMAIP1 (NOXA)

$1.602 .20 \quad$ DDIT3 (CHOP)

1.371 .66 ERN1 (IRE1)

3.042 .53 GADD45A

$-2.24 \quad-4.37$ HSPA8

$-2.91-1.91$ HSPA1A

$\begin{array}{lll}-1.73 & -2.88 \text { HSPA1B }\end{array}$

$-2.24 \quad-4.37$ HSPA8

0.00

Fig. 1 The NGS and pathway analyses of early gene transcripts dysregulated by C-1305 treatment in A549 cells. a The 2D chemical structure of C-1305 (5-((3-(dimethylamino)propyl)amino)-8-hydroxy-6H-[1,2,3] triazolo[4,5,1-de]acridin-6-one; $\left.\mathrm{C}_{18} \mathrm{H}_{19} \mathrm{~N}_{5} \mathrm{O}_{2}\right)$. b The unique early gene transcripts dysregulated after $8 \mathrm{~h}$ of treatment of A549 with $3 \mu \mathrm{M} C-1305$ were selected from the NGS experiments. Well-established gene transcripts with greater than 10 RPKMs per sample and with significance $(p \leq 0.05)$ greater for change in expression between C-1305-treated and control groups (no treatment and 24-h treatment) were used in pathway analyses. The Gene Ontology clusters are depicted for selected genes; clusters are listed followed by the $p$ values and enrichment scores calculated by Enricher, which is used to determine the percentage of the chart. The longer bar the lower p-value, while the darker the color, the more enriched the cluster. Only clusters with $p \leq 0.001$ were considered. $\mathbf{c}$ The heat map representing C-1305 exposure related expression changes in genes related to UPR and ER stress as observed in NGS experiments in A549 cells exposed to $3 \mu \mathrm{M}$ and $10 \mu \mathrm{M} \mathrm{C}-1305$ for $8 \mathrm{~h}$. Heat maps were generated with the Morpheus software (Morpheus, https://softw are.broadinstitute.org/morpheus). The color scale and values depict fold change (c) 
(CHOP)—Hs00358796_g1, ERN1 (IRE1)-Hs00980095_m1, PMAIP1 (NOXA)Hs00560402_m1, XBP1 (isoform 1and 2)—Hs00231936_m1, XBP1s_Hs03929085_g1.

\section{Western blots}

$\mathrm{XBP} 1 \mathrm{~s}$ protein detection was performed as described in [32]. Briefly, cells were lysed on ice for $15 \mathrm{~min}$ in RIPA buffer $[150 \mathrm{mM} \mathrm{NaCl}, 1 \% \mathrm{NP}-40,0.5 \%$ sodium deoxycholate, $0.1 \%$ SDS, and $50 \mathrm{mM}$ Tris- $\mathrm{HCl}(\mathrm{pH} 8.0)$ ] supplemented with Protease Inhibitor Complete Mini (00000011836170001; Roche, Basel, Switzerland). The insoluble material was removed by centrifugation at $15,000 \mathrm{~g}$ for $15 \mathrm{~min}$. Protein concentrations were determined by Bio-Rad Protein Assay (Bradford-based method; Bio-Rad, Hercules, CA, USA) using bovine serum albumin (BSA; MilliporeSigma) as the standard. Following the normalization of protein concentrations, lysates were mixed with an equal volume of $2 \times$ Laemmli sample buffer (Bio-Rad) and incubated for $5 \mathrm{~min}$ at $95{ }^{\circ} \mathrm{C}$ before separation by SDS-PAGE on stain-free TGX gradient gels (Bio-Rad). Following SDS-PAGE, the proteins were transferred to PVDF membranes (300 mA for 90 min at $4{ }^{\circ} \mathrm{C}$ ). The membranes were then blocked with BSA dissolved in PBS and Tween-20 (3\% BSA and $0.5 \%$ Tween-20 for $1-2 \mathrm{~h}$ ) followed by immunoblotting with the primary antibody for each experiment for XBP1s (mAb 12782; diluted at 1:1000; Cell Signaling Technology, Danvers, MA, USA). After the washing steps, the membranes were incubated with goat anti-rabbit IgG $(\mathrm{H}+\mathrm{L})$ horseradish peroxidase-conjugated secondary antibodies (BioRad) and detected using ECL (Amresco, Solon, OH, USA). Densitometry was performed using Image Lab software v.4.1 (Bio-Rad).

\section{Molecular docking}

The crystal structure of human phosphorylated IRE1 $\alpha$ in complex with ADP-Mg (PDB ID code 4YZD, RSCB Protein Data Bank) [33] was used for molecular docking performed in this study. The structure of IRE1 was prepared for docking analysis on the UCSF Chimera software package [34] where the multi-chain structure was converted to a monomeric structure (chain A), and water and ADP-Mg were deleted to enable testing of studied ligand binding. A mol2 file with all hydrogens and 3D coordinates of C-1305, 448C IRE1 [35], and 3,6 DMAD (9- $N$-[3-(dimethylamino)propyl]-3- $N, 3-N, 6-N, 6-N$-tetramethylacridine-3,6,9-triamine) [36] IRE1 inhibitors were generated using MarvinSketch (ver. 20.18.0 ChemAxon Ltd) [36]. Energy optimizations of C-1305, 448C, and 3,6-DMAD with 500 steps of the steepest descent algorithm using the MMFF94 force field were carried out for all 2D structures using the Avogadro 1.2.0 package software [37]. The minimized structures were used as inputs for ligand binding modeling. Furthermore, all three compounds were docked into their potential binding pockets of the native 3D structure of IRE1 proteins (PDB ID code 4YZD) with the aid of EDock that is based on replica-exchange Monte Carlo simulations that identifies high-quality blind docking sites [38]. Only protein fragments that are not well ordered in the crystal structure were predicted using the I-TASSER (Iterative Threading ASSEmbly Refinement), a part of EDock server. This simulation does not disturb the native IRE1 binding pocket structure. RMSD (UCSF Chimera) between 143 pruned atom pairs is 0.000 angstroms (across all 143 pairs: 0.000). For the docking analyses, only the best scoring results were used. The results of docking were visualized with UCSF Chimera. 


\section{In vitro kinase assay}

ERN1 (IRE1 $\alpha)$ Kinase Enzyme assays were performed using the luminescent ADP$\mathrm{Glo}^{\mathrm{TM}}$ assay kit (VA7146, Promega) that measures the generation of ADP by the protein kinase reaction that is measured by an increase in the luminescence signal in the presence of luminescent ADP-Glo ${ }^{\mathrm{TM}}$ reagent. All reagents were prepared according to the manufacturer's instructions. To determine the appropriate enzyme concentration for use in each inhibitor dose-response curve determination, a kinase titration was performed using $10 \mu \mathrm{M}$ ATP. Based on these results, a concentration of $5 \mathrm{ng}$ of IRE1 enzyme per reaction was chosen to determine the kinase inhibitory activity of C-1305 and 448C (SML0949, Sigma-Aldrich). Staurosporine (S6942-200UL, SigmaAldrich) was used as a control kinase inhibitor. All reactions were measured using the GloMax $^{\circledR}$-Multi Detection System (Promega). The results were expressed as remaining activity, normalized to the uninhibited control for $100 \%$ activity and to the fully inhibited one for $0 \%$ activity. To normalize the data from the following equation was used:

"\% Remaining activity $=100 \times(\mathrm{S}-\mathrm{B} / \mathrm{U}-\mathrm{B}) "$,

"S" being the signal obtained for each concentration of compound, "U" the signal produced by the uninhibited control (enzyme alone), and "B" the background produced by the fully inhibited control (no enzyme). The data were plotted and fit to sigmoidal curves using Origin Pro ver 7.0 (OriginLab Corporation, Northampton, MA, USA) to determine the $\mathrm{IC}_{50}$.

\section{Statistical analysis}

Results were expressed as a mean \pm standard deviation. Statistical significance was determined using the Student's t-test and ANOVA on ranks with $\mathrm{p}$-values below $p=0.05$ considered significant.

\section{Results}

We previously utilized a genome-wide approach to identify transcriptomic signatures of C-1305 cytotoxicity in lung cell lines and demonstrated that C-1305 promotes direct microtubule stabilization as a part of its mechanism of action that leads to apoptosis [21]. We also observed that C-1305 at concentrations up to $10 \mu \mathrm{M}$ had no significant effect on growth and survival of an adenocarcinoma lung cell line, A549, up to about $18 \mathrm{~h}$ [21]. To further evaluate the early transcriptomic signaling that contributes to C-1305's biological effects, we focused on the genome-wide consequences of $8 \mathrm{~h}$ exposure of A549 cells to $3 \mu \mathrm{M} \mathrm{C}-1305$, a concentration that did not affect cell survival during this time of exposure [21]. In this experiment, total RNA was extracted from the A549 cells that were exposed to C-1305 for $8 \mathrm{~h}$ and from $8 \mathrm{~h}$ DMSO vehicle-treated cells (controls), and then subjected to RNA sequencing. To focus only on the C-1305 early transcriptome changes, we corrected (subtracted out) the A549-C-1305-8 h treated gene set with the A549-8 h vehicle-treated gene set and also the previously obtained A549-C-1305-24 h treated gene set [21]. Our analysis was narrowed to the most significant expression changes $(p \leq 0.05)$. This 
approach resulted in the identification of 182 genes dysregulated specifically at the $\mathrm{C}-1305$ treatment $8 \mathrm{~h}$ time point and these genes were further subjected to gene ontology analysis using Enricher [29]. As shown in Fig. 1b, the cellular response to unfolded/misfolded proteins was the most significant assignment. Within this cluster of gene transcripts, the following genes' mRNA levels were downregulated upon C-1305 exposure: heat shock protein family A member 5 (HSPA5 aka BiP), XBP1, heat shock protein family A member 8 (HSPA8), heat shock protein family A member 1A (HSPA1A) and heat shock protein family A member 1B (HSPA1B) (Fig. 1c). Notably, the upregulated genes in this set were Bcl-2 binding component 3 ( $B B C 3$ aka PUMA), phorbol-12-myristate-13-acetate-induced protein 1 (PMAIP1 aka NOXA), activating transcription factor 3 (ATF3), DNA damage inducible alpha (GADD45A) as well as ERN1 (aka IRE1) and DNA damage inducible transcript 3 (DDIT3 aka CHOP) (Fig. 1c). Notably, similar and even more dramatic transcriptomic changes were also observed up on $8 \mathrm{~h}$ exposure to $10 \mu \mathrm{M}$ concentration of C-1305 (Fig. 1c).

Based on the results of the RNAseq-based approach, we speculated that C-1305 may impair endoplasmic reticulum (ER) protein homeostasis via downregulation of transcripts of chaperone (BiP) and proadaptive transcription factors (XBP1s) and this could lead to activation of UPR pathways. Furthermore, the UPR proapoptotic factors like CHOP, PUMA, NOXA and GADD45A were elevated at this time. To verify this observation, we performed qPCR analysis of these UPR related transcripts levels after $8 \mathrm{~h}$ $\mathrm{C}-1305$ treatments at $1 \mu \mathrm{M}, 3 \mu \mathrm{M}$ and $10 \mu \mathrm{M}$ concentrations in A549 as well as in a noncancer lung cell line 16HBE14o-, and in HeLa cells. We included HeLa cells since this cell line is a well recognized and characterized model for studying pharmacological ER stress and UPR induction, including the IRE1/XBP1s branch [39-47].

As shown in Fig. 2, the $8 \mathrm{~h} \mathrm{C}-1305$ exposure of all cell lines significantly reduced BiP expression and resulted in significant induction of ERN1 mRNA levels. Although, the cell lines differed between each other in terms of C-1305 dose response dependence and magnitudes of transcriptomic changes, the general compound's effects on BiP and ERN1 (IRE1) mRNA levels correlated fairly well with the C-1305 concentrations except for the $10 \mu \mathrm{M}$ concentration in the HeLa cells. In examining the effects of $\mathrm{C}-1305$ on the active isoform of $X B P 1, X B P 1 s$, the results indicated that the levels of this mRNA were dramatically lower in all three cell lines (Fig. 2c) which was surprising given that the ERN1 mRNA levels were increased.

In terms of the proapoptotic factors, there was no significant induction of $\mathrm{CHOP}$ observed in airway cells, 16HBE14o- and A549, after exposure to $1 \mu \mathrm{M}$ and $3 \mu \mathrm{M}$ C-1305, whereas it was in the HeLa cells at all three concentrations (Fig. 3a). Nevertheless, a moderate $C H O P$ induction was observed in the NGS analysis of A549 exposed to $3 \mu \mathrm{M} \mathrm{C}-1305$, however, this discrepancy results from the different gene expression normalization methods applied for NGS and qPCR data (global-DESeq2 and individual-GAPDH and TBP reference genes, respectively). In contrast, there was a significant induction of both proapoptotic NOXA and PUMA mRNA expression at all three concentrations in all of the tested cell lines (Fig. 3b, c). The collective data in Figs. 2 and 3 suggest that $\mathrm{C}-1305$ treatment induced IRE1, but paradoxically, decreased XBP1s mRNA expression, and that for the most part, the UPR prosurvival genes decreased and the proapoptotic genes increased. 

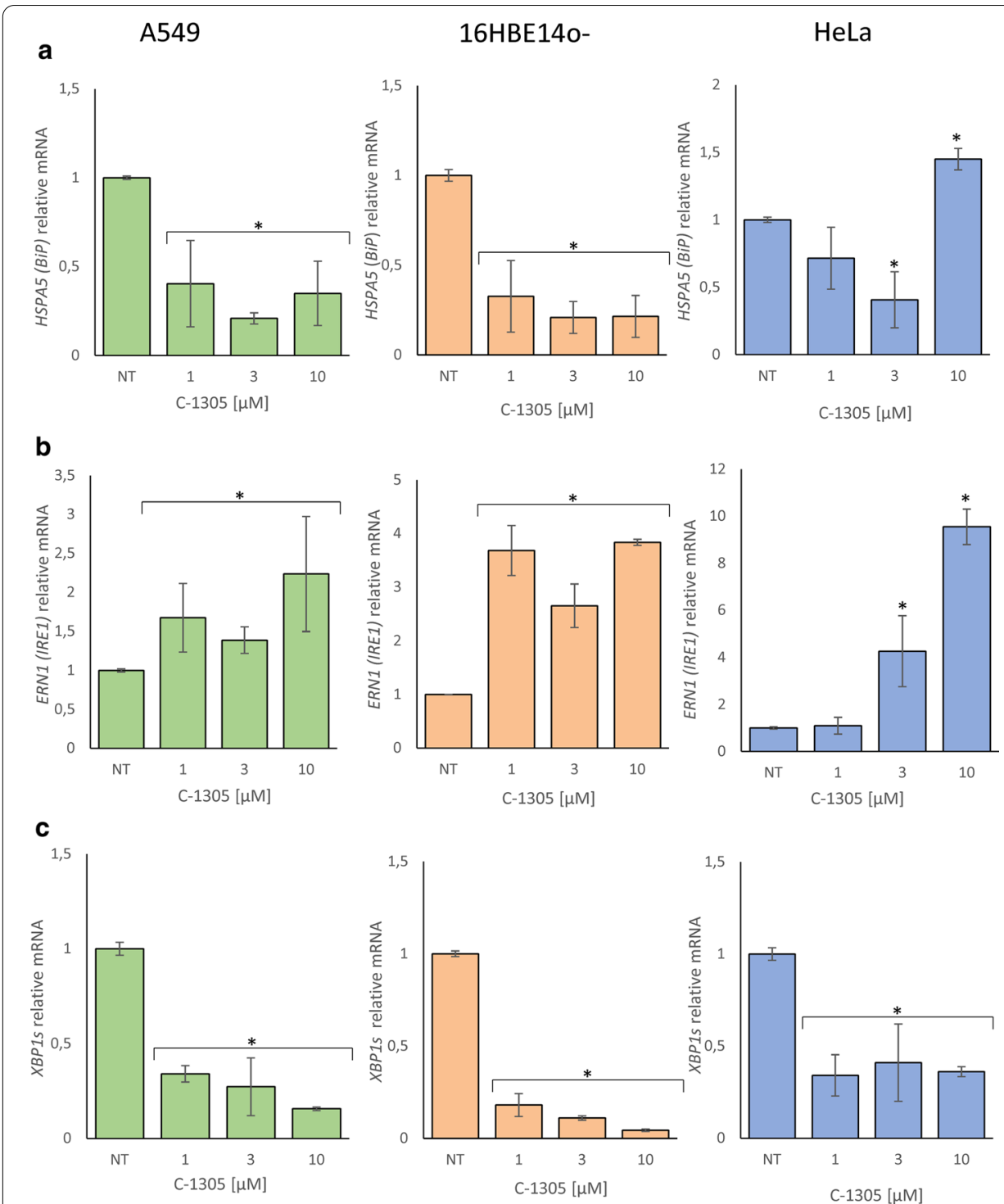

Fig. 2 C-1305-induced changes in a BiP, b ERN1, c XBP1s mRNA levels in A549, 16HBE140- and HeLa cells after $8 \mathrm{~h}$ of treatment. The results from 3 independent experiments $(n=9)$ are plotted normalized to GAPDH and TBP mRNA levels and expressed as a fold-change over the vehicle controls. Error bars represent standard deviations. Significant changes ( $p$-value $<0.05$ ) are marked with an asterisk

Based on these results, we next tested whether the decrease in XBP1s was due to a inhibition of IRE1 $\alpha$ endoribonuclease activity. We compared the C-1305 effectiveness in preventing IRE1 $\alpha$-dependent XBP1 mRNA splicing with the efficiency of commonly used IRE1 inhibitor 4 $\mu 8 \mathrm{C}[35,48]$ (Fig. 4a). As an ER stress induced XBP1 mRNA splicing model, we used HeLa cells treated for $6 \mathrm{~h}$ with the classical pharmacological stressor tunicamycin $(\mathrm{Tm}, 0.5 \mathrm{ug} / \mathrm{ml})$, a glycosylation inhibitor. We used HeLa cells for this experiment since they are commonly used in ER stress and UPR studies [39-43]. Previous studies using this model indicated that maximal XBP1s mRNA levels are observed after $6 \mathrm{~h}$ of treatment [44]. Furthermore, both treatments of HeLa cells with $\mathrm{C}-1305$ for $6 \mathrm{~h}$ or co-treatments with Tm and Tg had a limited effect on cell survival 

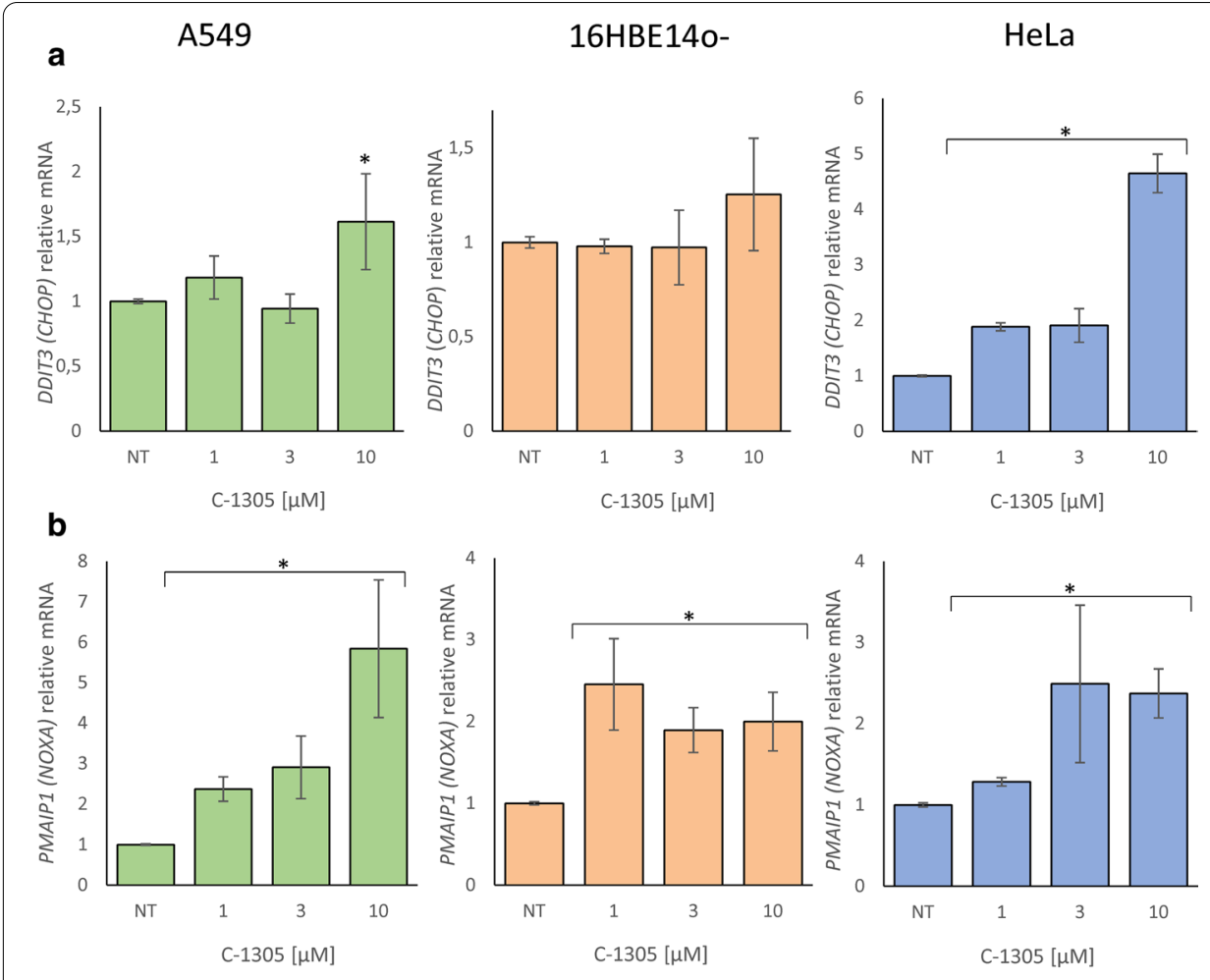

c
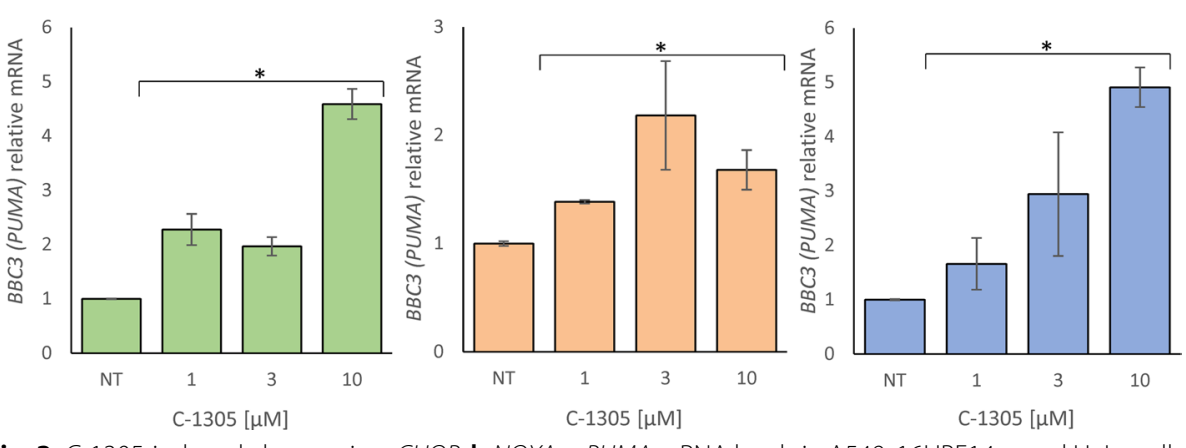

Fig. 3 C-1305-induced changes in a CHOP, b NOXA, c PUMA mRNA levels in A549, 16HBE140- and HeLa cells after $8 \mathrm{~h}$ of treatment. The results from 3 independent experiments $(n=9)$ are plotted normalized to GAPDH and TBP mRNA levels and expressed as a fold-change over the vehicle controls. Error bars represent standard deviations. Significant changes ( $p$-value $<0.05$ ) are marked with an asterisk

$\left(\mathrm{IC}_{50}=37,62 \mu \mathrm{M}\right.$ for $\mathrm{C}-1305, \mathrm{IC}_{50}=34,80 \mu \mathrm{M}$ for $\mathrm{C}-1305$ and $\mathrm{Tm} ; \mathrm{IC}_{50}=21,6 \mu \mathrm{M}$ for C-1305 and Tg; as monitored by the MTT assay, Additional file 1: Figure S1).

As shown in Fig. 4b, the use of Tm resulted in about a sevenfold induction of XBP1s mRNA, whereas use of $1 \mu \mathrm{M}, 10 \mu \mathrm{M}$ and $50 \mu \mathrm{M}$ of C-1305 resulted in dramatic reduction of XBP1s mRNA levels and appeared very similar to the $\mathrm{Tm} 4 \mu 8 \mathrm{C}$ treatments. Furthermore, the XBP1s protein reduction was similar for both the $\mathrm{C}-1305$ and $4 \mu 8 \mathrm{C}$ (Fig. 4c, d), suggesting that C-1305 inhibited the IRE1 endoribonuclease activity and the subsequent production of XBP1s.

To characterize the C-1305 as a potential IRE1 inhibitor, we used the HeLa model to determine C-1305's IRE1 $\alpha$ endoribonuclease activity $\mathrm{IC}_{50}$ values based on the 
a<smiles>Cc1cc(=O)oc2c(C=O)c(O)ccc12</smiles>

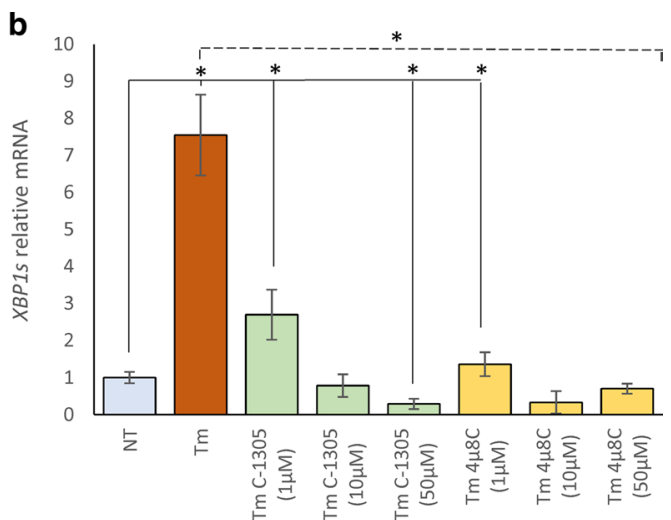

C

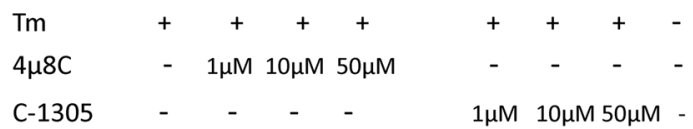

- - - - -

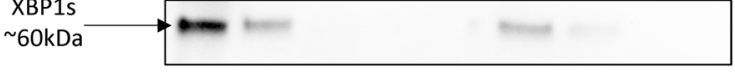

Total Protein
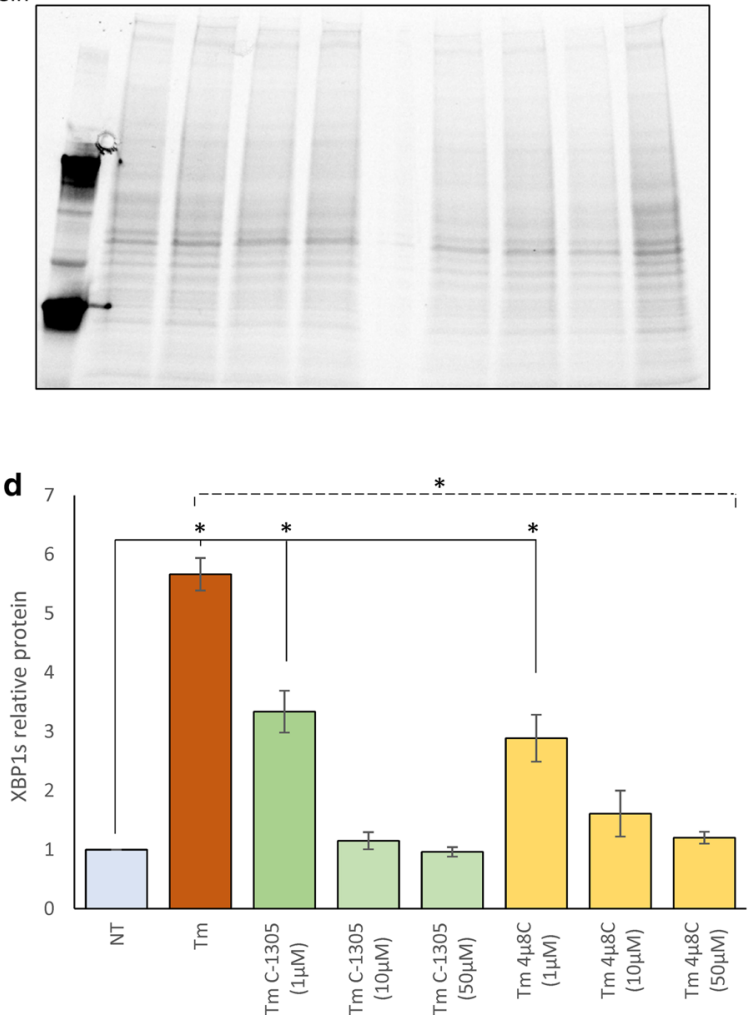

Fig. 4 C-1305-prevents IRE1 a-dependent XBP1 mRNA splicing during ER stress. a The 2D chemical structure of $4 \mu 8 \mathrm{C}$ (7-Hydroxy-4-methyl-2-oxo-2H-chromene-8-carbaldehyde, $\mathrm{C}_{11} \mathrm{H}_{8} \mathrm{O}_{4}$ ). $\mathbf{b}$ HeLa cells were treated with ER stressors (Tm, $0.5 \mu \mathrm{g} / \mathrm{ml})$ for $6 \mathrm{~h}$ in a presence of specified concentrations of $\mathrm{C}-1305$ and $4 \mu 8 \mathrm{C}$. Following the treatments, the XBP1s mRNA levels were accessed with qPCR and expressed as a fold-change over the no stress controls. The results from 3 independent experiments $(n=9)$ are plotted normalized to GAPDH and TBP mRNA. Error bars represent standard deviations. Significant changes ( $p$-value $<0.05)$ are marked with an asterisk. $\mathbf{c}$ The corresponding changes in XBP1s protein levels were evaluated by Western blot (d) normalized to total protein levels and related no stress control. The data from 3 independent experiments were analyzed. ${ }^{*} p<0.05$ was considered significant. The raw data are provided in Additional file 1 
(See figure on next page.)

Fig. 5 The XBP1s mRNA-based determination of C-1305 impact on IRE1 a endoribonuclease activity in ER stressed HeLa cells. HeLa cells were treated with ER stressors (Tm, $0.5 \mu \mathrm{g} / \mathrm{ml}$ and Tg, $25 \mathrm{nM}$ ), for $6 \mathrm{~h}$ in a presence of specified concentrations of $\mathrm{C}-1305$ and $4 \mu 8 \mathrm{C}$. Following the treatments, the XBP1s mRNA levels were accessed with $\mathrm{qPCR}$ and expressed as a change versus ER stressed cells treated with vehicle. The results from 3 independent experiments $(n=9)$ are plotted normalized to GAPDH and TBP mRNA. Error bars represent standard deviations. Concentration response curves and $I C_{50}$ values of $\mathbf{a} C-1305$ and $\mathbf{b} 4 \mu 8 \mathrm{C}$ in Tm treated cells were determined using Sigma Plot 1.1 software. Similar approach was used to determine Concentration response curves and $I_{50}$ values of $\mathbf{c} C-1305$ and $\mathbf{d} 4 \mu 8 \mathrm{C}$ in Tg treated cells. The IRE1 a kinase assays were performed in the presence of serial dilution and were measured with ADP-Glo kinase assay. Concentration response curve and $I_{50}$ values of $\mathbf{e} C-1305, \mathbf{f} 4 \mu 8 \mathrm{C}$ and $\mathbf{g}$ staurosporine (used as a control of kinase activity) were determined using Origin Pro software. The results were expressed as remaining activity, normalized to the uninhibited control for $100 \%$ activity and to the fully inhibited one for $0 \%$ activity as described in "Materials and methods". Data are plotted as means \pm SD from triplicate measurements of two independent measurements $(n=6)$

measurement of XBP1s mRNA levels and used $4 \mu 8 \mathrm{C}$ as our control. As shown in Fig. 5a, in Tm treated HeLa cells, the $\mathrm{IC}_{50}$ for $\mathrm{C}-1305$ was $1.017 \mu \mathrm{M}$, whereas the $\mathrm{IC}_{50}$ for $4 \mu 8 \mathrm{C}$ under the same conditions was $0.142 \mu \mathrm{M}$ (Fig. $5 \mathrm{~b}$ ). Next, we tested another common ER stress model thapsigargin ( $\mathrm{Tg}, 25 \mathrm{nM})$, a noncompetitive inhibitor of the endoplasmic reticulum $\mathrm{Ca}^{2+}$ ATPase that results in higher induction of XBP1s mRNA $[23,32]$. In this case, higher concentrations of both $\mathrm{C}-1305$ and $4 \mu 8 \mathrm{C}$ were necessary to reduce the XBP1s mRNA levels $\left(\mathrm{IC}_{50}=16.821 \mu \mathrm{M}\right.$ for $\mathrm{C}-1305$ and $\mathrm{IC}_{50}=1.66 \mu \mathrm{M}$ for $4 \mu 8 \mathrm{C}$, Fig. $5 \mathrm{c}, \mathrm{d}$ ). Taken together, the results suggest that $\mathrm{C}-1305$ is an efficient inhibitor of IRE1 $\alpha$ and this compound works independently of the mechanism of pharmacological ER stress induction.

Using purified IRE1 protein, we next determined C-1305's and 4 $48 \mathrm{C}$ 's effects on the IRE1 $\alpha$ kinase activity in vitro and used staurosporine as a reference control. As shown in Fig. 5e, the C-1305 has no effect on IRE1 $\alpha$ kinase activity, whereas $4 \mu 8 \mathrm{C}$ was able to inhibit half of IRE1 phosphorylation at $31.25 \mu \mathrm{M}$ concentration (Fig. 5f). These results suggest that C-1305 mechanism of action is based on inhibiting IRE1 $\alpha$ endoribonuclease activity rather than kinase activity, whereas $4 \mu 8 \mathrm{C}$ can block both endoribonuclease and kinase activity of IRE1. That being said, $4 \mu 8 \mathrm{C} \mathrm{IC} \mathrm{I}_{50}$ value for the kinase activity is remarkably high when compared with staurosporine $(1.98 \mathrm{nM}$, Fig. $5 \mathrm{~g})$, and significantly higher than the concentrations required to reduce the endoribonuclease activity of IRE1 $\alpha$ based on the XBP1s message readout.

Since our results suggested that C-1305 may inhibit IRE1 $\alpha$ via direct interaction with its RNAse domain, we evaluated docking of C-1305 targeting the catalytic site of the RNase domain using molecular docking analysis (Fig. 6). The model of IRE1 $\alpha$ in complex with C-1305 inhibitor obtained in the docking analysis suggests that this molecule can form hydrophobic interactions with F889 and L886 residues, a hydrogen bond with Y892 and N906 (Fig. 6a). Molecular docking results clearly suggest that triazole ring can interact with both Lysine via H-bonding and Leucine via a pialkyl interaction. These interactions could stabilize $\mathrm{C} 1305$ in the ribonuclease active site of IRE1 $\alpha$. In contrast, the docking of $4 \mu 8 \mathrm{c}$ to IRE1 $\alpha$ shows interactions with H910, N906, K907, and E913 and was similar to the previous docking model published by [35], Hanwell, Curtis [37] indicated that Y892, F889, N906, K907, and H910 residues of IRE1 $\alpha$ interact with $4 \mu 8 \mathrm{c}$ (Fig. $6 \mathrm{~b}$ ). The mode of action of $4 \mu 8 \mathrm{c}$ is related 


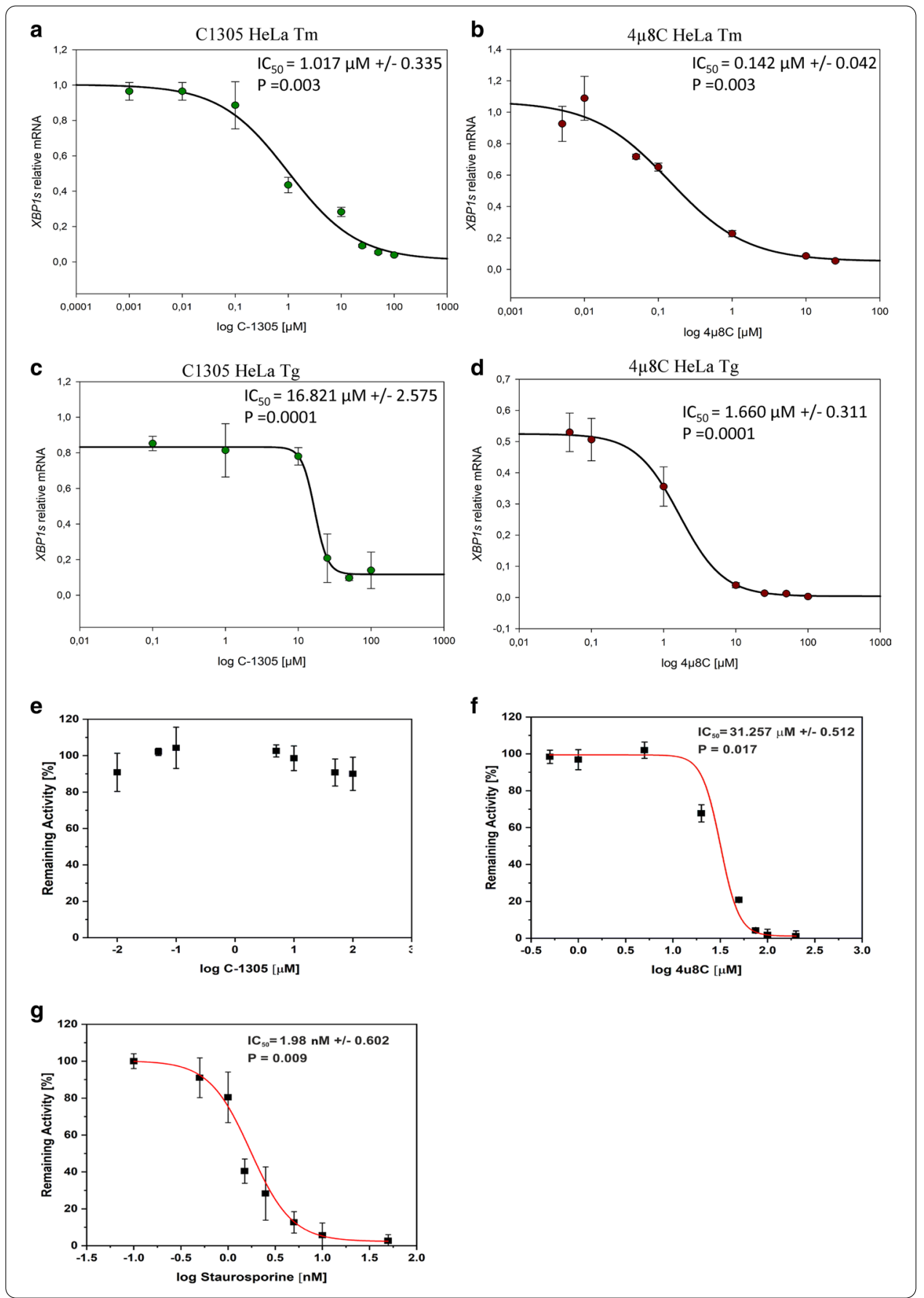

to the formation of a Schiff base with K907 residue. Despite the fact that C1307 does not have an aldehyde group, it is conceivable that it forms an imine bond with K907 due to the presence of a carbonyl group in its structure. Since structurally C-1305 is related to a known IRE1 $\alpha$ inhibitor, acridine derivative 3,6-DMAD [36], we also prepared a docking model of 3,6-DMAD with IRE1 $\alpha$ (Fig. 6c) and showed the interaction of 3,6-DMAD with H910, N906, K907, L886, Y892, F889, and E913 residues of IRE1 $\alpha$ that are present in the catalytic site of the RNAse domain of IRE1 $\alpha$. Taken 


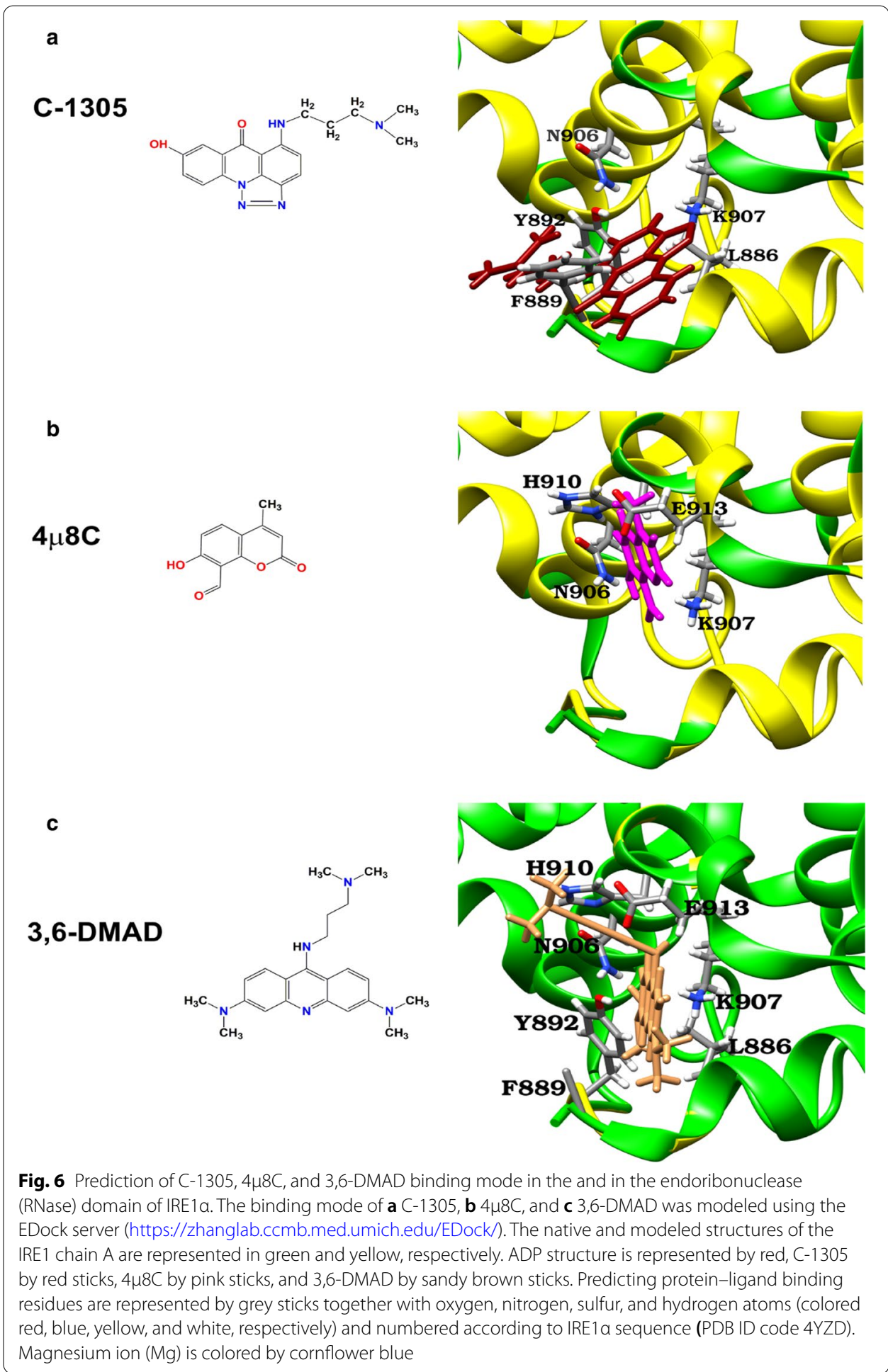

together, the results of the computational modeling strongly support the hypothesis that $\mathrm{C}-1305$ is a direct IRE1 $\alpha$ inhibitor, however, further experimental studies will be required to confirm these findings. 


\section{Discussion}

The IRE1 $\alpha$-dependent pathway has been considered as a one of main transducers of the

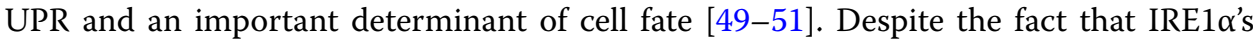
molecular activities are mostly related to facilitating cellular survival, during irrevocable ER stress, this enzyme can also contribute to accumulation of proinflammatory and apoptotic factors [52]. Thus, gaining control over IRE1 $\alpha$ 's activities with small molecules remains a promising approach to improving cancer treatments by inhibiting IRE1 $\alpha$ activity during the early stages of tumorigenesis [53-55] and by preventing tumor progression and metastasis either by utilizing proapoptotic abilities of this enzyme [4] or inducing apoptosis through other signaling pathways such as PERK. Nevertheless, most studies focus on inhibiting IRE1 $\alpha$ activity to impair the adaptation of tumor cells to their cellular stressors. Currently, numerous compounds has been shown to be highly selective in preventing IRE1 $\alpha$ kinase, RNAse or both activities and are characterized by $\mathrm{EC}_{50}$ values ranging from 0.02 to $20 \mu \mathrm{M}$ (reviewed in [4]). Furthermore, molecules such as astoyocamycin, doxorubicin, quinotrierixin, and trierixin were shown to inhibit IRE1 $\alpha$ / XBP1s activity in vitro and in vivo despite no clear determination of their mechanism of their action with IRE1 $\alpha$ [4]. Although some structural similarities can be found among known IRE1 $\alpha$ inhibitors, their number remains limited, and many of the compounds have been identified in high-throughput screens [4]. Hence, identification of novel structural motifs responsible for preventing IRE1 $\alpha$ kinase or RNAse activity may promote a more rational design and development of better IRE1 $\alpha$ inhibitors.

In this study, based on observations from an unbiased transcriptomic screen for molecular mechanisms of action of cytotoxic triazoloacridone C-1305 in cancer cell lines [21], we identified that a known topoisomerase inhibitor and microtubule-stabilizing agent can also inhibit XBP1s activity, presumably by inhibiting the endoribonuclease activity of IRE1 $\alpha$. Our studies indicate that C-1305 treatment reduces XBP1s mRNA levels and downregulation of ER protein folding machinery including BiP and the accumulation of ER stress-related apoptotic factors mRNAs including NOXA and PUMA. We also verified and compared C-1305 to $4 \mu 8 \mathrm{C}$, a well-established IRE1 $\alpha$ endoribonuclease inhibitor, and found using XBP1s message as our readout that the $\mathrm{IC}_{50}$ for $4 \mu 8 \mathrm{C}$ was $0.142 \mu \mathrm{M}$, which compares favorably to the literature range of 0.076 to $6.9 \mu \mathrm{M}$ [35]).

Although we found that C-1305 had no kinase inhibitory activity, we did observe that $4 \mu 8 \mathrm{C}$ did have a modest effect on kinase activity $\left(\mathrm{IC}_{50}\right.$ of $\left.31 \mu \mathrm{M}\right)$. Although this compound was been initially assigned as an IRE1 $\alpha$ RNAse inhibitor, our observation is consistent with previous reports of Cross, Bond [35] who demonstrated that $4 \mu 8 \mathrm{C}$ can inhibit IRE1 autophosphorylation in cell-free assays via Schiff base formation with IRE1 $\alpha$ K599 in the absence of ADP. However, this cellular nucleotide prevents 4u8C from targeting IRE1 $\alpha$ K599 intracellularly [35].

Furthermore, our model of IRE1 $\alpha$ in complex with C-1305 inhibitor obtained in the docking analysis strongly support the hypothesis that C-1305 is a direct IRE1 $\alpha$ inhibitor, however, further experimental studies will be required to confirm these findings.

In conclusion, we identified C-1305 as potential inhibitor of IRE1 $\alpha$ RNAse activity and previous studies reported this compound is potent cytotoxic agent and an atypical topoisomerase poison and microtubule stabilizing agent. C-1305 may provide a rational platform for further development of this class of compounds in anti-cancer therapies. 


\section{Abbreviations}

UPR: Unfolded protein response; IRE1 a: Inositol-requiring protein 1 alpha; PERK: Protein kinase RNA-like ER kinase; ATF6: Activating transcription factor 6; RIDD: Regulated IRE1-dependent decay; XBP1: X-box binding protein 1; XBP1s: Spliced XBP1; ERAD: ER associated protein degradation; Rnase: Endoribonuclease.

\section{Supplementary Information}

The online version contains supplementary material available at https://doi.org/10.1186/s11658-021-00255-y.

Additional file 1: Evaluation of C-1305 cytotoxicity in HeLa cells exposed for 6 hours to different concentrations of C-1305 and ER stressors, and supplementary materials for Figure 4 (three examples of the uncropped Western blots and SDS Page gels used to follow XBP1s changes).

\section{Acknowledgements}

We would like to thank Dr. Magdalena Dudkowska and Dr. Karol Krzymiński for their kind assistance.

\section{Authors' contributions}

Conceived and designed the experiments: SB, RB. Performed the experiments: SB, JK, RB. Analyzed the data: SB, JK, DKC, $A P$, JFC. Contributed reagents/materials/resources: MB, RB. Wrote the paper: SB, RB, JFC. All authors read and approved the final manuscript.

\section{Funding}

This research was funded by This work was funded by National Center for Research and Development Program under contract Strategmed3/306853/9/NCBR/2017 (TARGETTELO) to R.B.

\section{Availability of data and materials}

Deep sequencing data were deposited in Gene Expression Omnibus (GEO) at Accession number: GSE143649.

\section{Declarations}

Ethics approval and consent to participate

Not applicable.

\section{Consent for publication}

Not applicable.

\section{Competing interests}

The authors declare no conflict of interest. The funders had no role in the design of the study; in the collection, analyses, or interpretation of data; in the writing of the manuscript, or in the decision to publish the results.

\section{Author details}

' Department of Inorganic Chemistry, Medical University of Gdansk, Hallera 107, 80-416 Gdańsk, Poland. ${ }^{2}$ Department of Biology and Pharmaceutical Botany, Medical University of Gdansk, Hallera 107, 80-416 Gdańsk, Poland. ${ }^{3}$ Department of Genetics, Heflin Center for Genomic Science, University of Alabama at Birmingham, Birmingham, AL 35233, USA.

${ }^{4}$ Department of Organic Chemistry, Medical University of Gdansk, Gdansk, Poland. ${ }^{5}$ Department of Pharmaceutical Technology and Biochemistry, Faculty of Chemistry, Gdansk University of Technology, 80-233 Gdańsk, Poland. ${ }^{6}$ Department of Cell, Developmental and Integrative Biology, University of Alabama at Birmingham, Birmingham, AL 35233, USA.

Received: 29 January 2021 Accepted: 9 March 2021

Published online: 17 March 2021

\section{References}

1. Madden E, Logue SE, Healy SJ, Manie S, Samali A. The role of the unfolded protein response in cancer progression: from oncogenesis to chemoresistance. Biol Cell. 2019;111(1):1-17. https://doi.org/10.1111/boc.201800050.

2. Schroder M, Kaufman RJ. ER stress and the unfolded protein response. Mutat Res. 2005;569(1-2):29-63. https://doi. org/10.1016/j.mrfmmm.2004.06.056.

3. Sano R, Reed JC. ER stress-induced cell death mechanisms. Biochem Biophys Acta. 2013;1833(12):3460-70. https:// doi.org/10.1016/j.bbamcr.2013.06.028.

4. Raymundo DP, Doultsinos D, Guillory X, Carlesso A, Eriksson LA, Chevet E. Pharmacological targeting of IRE1 in cancer. Trends Cancer. 2020;6(12):1018-30. https://doi.org/10.1016/j.trecan.2020.07.006.

5. Zhao N, Cao J, Xu L, Tang Q, Dobrolecki LE, Lv X, et al. Pharmacological targeting of MYC-regulated IRE1/XBP1 pathway suppresses MYC-driven breast cancer. J Clin Invest. 2018;128(4):1283-99. https://doi.org/10.1172/JCl95873.

6. Ferri E, Le Thomas A, Wallweber HA, Day ES, Walters BT, Kaufman SE, et al. Activation of the IRE1 RNase through remodeling of the kinase front pocket by ATP-competitive ligands. Nat Commun. 2020;1 1(1):6387. https://doi. org/10.1038/s41467-020-19974-5. 
7. Yoshida H, Matsui T, Yamamoto A, Okada T, Mori K. XBP1 mRNA is induced by ATF6 and spliced by IRE1 in response to ER stress to produce a highly active transcription factor. Cell. 2001;107(7):881-91. https://doi.org/10.1016/S0092 $-8674(01) 00611-0$.

8. Back SH, Lee K, Vink E, Kaufman RJ. Cytoplasmic IRE1 alpha-mediated XBP1 mRNA splicing in the absence of nuclear processing and endoplasmic reticulum stress. J Biol Chem. 2006;281(27):18691-706. https://doi.org/10.1074/jbc. M602030200.

9. Lee K, Tirasophon W, Shen X, Michalak M, Prywes R, Okada T, et al. IRE1-mediated unconventional mRNA splicing and S2P-mediated ATF6 cleavage merge to regulate XBP1 in signaling the unfolded protein response. Genes Dev. 2002;16(4):452-66. https://doi.org/10.1101/gad.964702

10. Uemura A, Oku M, Mori K, Yoshida H. Unconventional splicing of XBP1 mRNA occurs in the cytoplasm during the mammalian unfolded protein response. J Cell Sci. 2009;122(Pt 16):2877-86. https://doi.org/10.1242/jcs.040584.

11. Schroder M, Kaufman RJ. The mammalian unfolded protein response. Ann Rev Biochem. 2005;74:739-89. https:// doi.org/10.1146/annurev.biochem.73.011303.074134.

12. Bartoszewska S, Collawn JF. Unfolded protein response (UPR) integrated signaling networks determine cell fate during hypoxia. Cell Mol Biol Lett. 2020;25:18. https://doi.org/10.1186/s11658-020-00212-1.

13. Karagoz GE, Acosta-Alvear D, Walter P. The unfolded protein response: detecting and responding to fluctuations in the protein-folding capacity of the endoplasmic reticulum. Cold Spring Harb Perspect Biol. 2019;11(9):a033886. https://doi.org/10.1101/cshperspect.a033886.

14. Chen S, Chen J, Hua X, Sun Y, Cui R, Sha J, et al. The emerging role of XBP1 in cancer. Biomed Pharmacother. 2020;1 127:110069. https://doi.org/10.1016/j.biopha.2020.110069.

15. Davies MP, Barraclough DL, Stewart C, Joyce KA, Eccles RM, Barraclough R, et al. Expression and splicing of the unfolded protein response gene XBP-1 are significantly associated with clinical outcome of endocrine-treated breast cancer. Int J Cancer. 2008;123(1):85-8. https://doi.org/10.1002/ijc.23479.

16. Bae J, Samur M, Munshi A, Hideshima T, Keskin D, Kimmelman A, et al. Heteroclitic XBP1 peptides evoke tumor-specific memory cytotoxic $T$ lymphocytes against breast cancer, colon cancer, and pancreatic cancer cells. Oncoimmunology. 2014;3(12):e970914. https://doi.org/10.4161/21624011.2014.970914.

17. Banerjee A, Ahmed H, Yang P, Czinn SJ, Blanchard TG. Endoplasmic reticulum stress and IRE-1 signaling cause apoptosis in colon cancer cells in response to andrographolide treatment. Oncotarget. 2016;7(27):41432-44. https://doi. org/10.18632/oncotarget.9180.

18. Samanta S, Tamura S, Dubeau L, Mhawech-Fauceglia P, Miyagi Y, Kato H, et al. Clinicopathological significance of endoplasmic reticulum stress proteins in ovarian carcinoma. Sci Rep. 2020;10(1):2160. https://doi.org/10.1038/s4159 8-020-59116-x.

19. McGrath EP, Logue SE, Mnich K, Deegan S, Jager R, Gorman AM, et al. The unfolded protein response in breast cancer. Cancers (Basel). 2018;10(10):344. https://doi.org/10.3390/cancers10100344.

20. Sabisz M, Wesierska-Gadek J, Skladanowski A. Increased cytotoxicity of an unusual DNA topoisomerase II inhibitor compound C-1305 toward HeLa cells with downregulated PARP-1 activity results from re-activation of the p53 pathway and modulation of mitotic checkpoints. Biochem Pharmacol. 2010;79(10):1387-97. https://doi.org/10.1016/j. bcp.2009.12.023.

21. Kroliczewski J, Bartoszewska S, Dudkowska M, Janiszewska D, Biernatowska A, Crossman DK, et al. Utilizing genomewide mRNA profiling to identify the cytotoxic chemotherapeutic mechanism of triazoloacridone C-1305 as direct microtubule stabilization. Cancers (Basel). 2020;12(4):864. https://doi.org/10.3390/cancers12040864.

22. Cozens AL, Yezzi MJ, Kunzelmann K, Ohrui T, Chin L, Eng K, et al. CFTR expression and chloride secretion in polarized immortal human bronchial epithelial cells. Am J Respir Cell Mol Biol. 1994;10(1):38-47. https://doi.org/10.1165/ajrcm b.10.1.7507342.

23. Bartoszewski R, Gebert M, Janaszak-Jasiecka A, Cabaj A, Kroliczewski J, Bartoszewska S, et al. Genome-wide mRNA profiling identifies RCAN1 and GADD45A as regulators of the transitional switch from survival to apoptosis during ER stress. FEBS J. 2020;287(14):2923-47. https://doi.org/10.1111/febs.15195.

24. Cholody WM, Martelli S, Konopa J. 8-Substituted 5-[(aminoalkyl)amino]-6H-v-triazolo[4,5,1-de]acridin-6-ones as potential antineoplastic agents. Synthesis and biological activity. J Med Chem. 1990;33(10):2852-6. https://doi. org/10.1021/jm00172a028.

25. Gebert M, Jaskiewicz M, Moszynska A, Collawn JF, Bartoszewski R. The effects of single nucleotide polymorphisms in cancer RNAi therapies. Cancers (Basel). 2020;12(11):3119. https://doi.org/10.3390/cancers12113119.

26. Trapnell C, Williams BA, Pertea G, Mortazavi A, Kwan G, van Baren MJ, et al. Transcript assembly and quantification by RNA-Seq reveals unannotated transcripts and isoform switching during cell differentiation. Nat Biotechnol. 2010:28(5):511-5. https://doi.org/10.1038/nbt.1621.

27. Anders S, Pyl PT, Huber W. HTSeq — a Python framework to work with high-throughput sequencing data. Bioinformatics. 2015;31(2):166-9. https://doi.org/10.1093/bioinformatics/btu638.

28. Love MI, Huber W, Anders S. Moderated estimation of fold change and dispersion for RNA-seq data with DESeq2. Genome Biol. 2014;15(12):550. https://doi.org/10.1186/s13059-014-0550-8.

29. Kuleshov MV, Jones MR, Rouillard AD, Fernandez NF, Duan Q, Wang Z, et al. Enrichr: a comprehensive gene set enrichment analysis web server 2016 update. Nucleic Acids Res. 2016;44(W1):W90-7. https://doi.org/10.1093/nar/ gkw377.

30. Bartoszewski R, Serocki M, Janaszak-Jasiecka A, Bartoszewska S, Kochan-Jamrozy K, Piotrowski A, et al. miR-200b downregulates Kruppel Like Factor 2 (KLF2) during acute hypoxia in human endothelial cells. Eur J Cell Biol. 2017;96(8):758-66. https://doi.org/10.1016/j.ejcb.2017.10.001.

31. Livak KJ, Schmittgen TD. Analysis of relative gene expression data using real-time quantitative PCR and the 2(-Delta Delta C(T)) Method. Methods (San Diego, Calif). 2001;25(4):402-8. https://doi.org/10.1006/meth.2001.1262.

32. Bartoszewska S, Cabaj A, Dabrowski M, Collawn JF, Bartoszewski R. miR-34c-5p modulates X-box-binding protein 1 (XBP1) expression during the adaptive phase of the unfolded protein response. FASEB J. 2019;33(10):11541-54. https://doi.org/10.1096/f.201900600RR. 
33. Concha NO, Smallwood A, Bonnette W, Totoritis R, Zhang G, Federowicz K, et al. Long-range inhibitor-induced conformational regulation of human IRE1 alpha endoribonuclease activity. Mol Pharmacol. 2015;88(6):1011-23. https:// doi.org/10.1124/mol.115.100917.

34. Pettersen EF, Goddard TD, Huang CC, Couch GS, Greenblatt DM, Meng EC, et al. UCSF Chimera-a visualization system for exploratory research and analysis. J Comput Chem. 2004;25(13):1605-12. https://doi.org/10.1002/jcc.20084.

35. Cross BC, Bond PJ, Sadowski PG, Jha BK, Zak J, Goodman JM, et al. The molecular basis for selective inhibition of unconventional mRNA splicing by an IRE1-binding small molecule. Proc Natl Acad Sci USA. 2012;109(15):E869-78. https://doi.org/10.1073/pnas.1115623109.

36. Jiang D, Tam AB, Alagappan M, Hay MP, Gupta A, Kozak MM, et al. Acridine derivatives as inhibitors of the IRE1 alphaXBP1 pathway are cytotoxic to human multiple myeloma. Mol Cancer Ther. 2016;15(9):2055-65. https://doi. org/10.1158/1535-7163.MCT-15-1023.

37. Hanwell MD, Curtis DE, Lonie DC, Vandermeersch T, Zurek E, Hutchison GR. Avogadro: an advanced semantic chemical editor, visualization, and analysis platform. J Cheminform. 2012;4(1):17. https://doi.org/10.1186/1758-2946-4-17.

38. Zhang W, Bell EW, Yin M, Zhang Y. EDock: blind protein-ligand docking by replica-exchange monte carlo simulation. J Cheminform. 2020;12(1):37. https://doi.org/10.1186/s13321-020-00440-9.

39. Li J, Ni M, Lee B, Barron E, Hinton DR, Lee AS. The unfolded protein response regulator GRP78/BiP is required for endoplasmic reticulum integrity and stress-induced autophagy in mammalian cells. Cell Death Differ. 2008;15(9):1460-71. https://doi.org/10.1038/cdd.2008.81.

40. Bartoszewski R, Brewer JW, Rab A, Crossman DK, Bartoszewska S, Kapoor N, et al. The unfolded protein response (UPR)-activated transcription factor X-box-binding protein 1 (XBP1) induces microRNA-346 expression that targets the human antigen peptide transporter 1 (TAP1) mRNA and governs immune regulatory genes. J Biol Chem. 2011;286(48):41862-70. https://doi.org/10.1074/jbc.M111.304956.

41. Shen J, Chen X, Hendershot L, Prywes R. ER stress regulation of ATF6 localization by dissociation of BiP/GRP78 binding and unmasking of Golgi localization signals. Dev Cell. 2002;3(1):99-111. https://doi.org/10.1016/s1534 $-5807(02) 00203-4$.

42. Iurlaro R, Munoz-Pinedo C. Cell death induced by endoplasmic reticulum stress. FEBS J. 2016;283(14):2640-52. https ://doi.org/10.1111/febs.13598.

43. Bartoszewski R, Rab A, Fu L, Bartoszewska S, Collawn J, Bebok Z. CFTR expression regulation by the unfolded protein response. Methods Enzymol. 2011;491:3-24. https://doi.org/10.1016/B978-0-12-385928-0.00001-8.

44. Byrd AE, Aragon IV, Brewer JW. MicroRNA-30c-2* limits expression of proadaptive factor XBP1 in the unfolded protein response. J Cell Biol. 2012;196(6):689-98. https://doi.org/10.1083/jcb.201201077.

45. Prasad V, Suomalainen M, Jasiqi Y, Hemmi S, Hearing P, Hosie L, et al. The UPR sensor IRE1 alpha and the adenovirus E3-19K glycoprotein sustain persistent and lytic infections. Nat Commun. 2020;1 1(1):1997. https://doi.org/10.1038/ s41467-020-15844-2.

46. LiY, Jiang W, Niu Q, Sun Y, Meng C, Tan L, et al. elF2alpha-CHOP-BCI-2/JNK and IRE1alpha-XBP1/JNK signaling promote apoptosis and inflammation and support the proliferation of Newcastle disease virus. Cell Death Dis. 2019;10(12):891. https://doi.org/10.1038/s41419-019-2128-6.

47. Wu Y, Li X, Jia J, Zhang Y, Li J, Zhu Z, et al. Transmembrane E3 ligase RNF183 mediates ER stress-induced apoptosis by degrading Bcl-XL. Proc Natl Acad Sci USA. 2018;115(12):E2762-71. https://doi.org/10.1073/pnas.1716439115.

48. Moszynska A, Collawn JF, Bartoszewski R. IRE1 endoribonuclease activity modulates hypoxic HIF-1alpha signaling in human endothelial cells. Biomolecules. 2020;10(6):895. https://doi.org/10.3390/biom10060895.

49. Chen Y, Brandizzi F. IRE1: ER stress sensor and cell fate executor. Trends Cell Biol. 2013;23(11):547-55. https://doi. org/10.1016/j.tcb.2013.06.005.

50. Shemorry A, Harnoss JM, Guttman O, Marsters SA, Komuves LG, Lawrence DA, et al. Caspase-mediated cleavage of IRE1 controls apoptotic cell commitment during endoplasmic reticulum stress. Elife. 2019;8:e47084. https://doi. org/10.7554/eLife.47084.

51. Chang TK, Lawrence DA, Lu M, Tan J, Harnoss JM, Marsters SA, et al. Coordination between two branches of the unfolded protein response determines apoptotic cell fate. Mol Cell. 2018;71(4):629-36.e5. https://doi.org/10.1016/j. molcel.2018.06.038.

52. Rosen DA, Seki SM, Fernandez-Castaneda A, Beiter RM, Eccles JD, Woodfolk JA, et al. Modulation of the sigma-1 receptor-IRE1 pathway is beneficial in preclinical models of inflammation and sepsis. Sci Transl Med. 2019;11(478):eaau5266. https://doi.org/10.1126/scitransImed.aau5266.

53. Huber AL, Lebeau J, Guillaumot P, Petrilli V, Malek M, Chilloux J, et al. p58(IPK)-mediated attenuation of the proapoptotic PERK-CHOP pathway allows malignant progression upon low glucose. Mol Cell. 2013;49(6):1049-59. https:// doi.org/10.1016/..molcel.2013.01.009.

54. Logue SE, McGrath EP, Cleary P, Greene S, Mnich K, Almanza A, et al. Inhibition of IRE1 RNase activity modulates the tumor cell secretome and enhances response to chemotherapy. Nat Commun. 2018;9(1):3267. https://doi. org/10.1038/s41467-018-05763-8.

55. Bouchecareilh M, Chevet E, Bikfalvi A, Moenner M, Drogat B, Auguste P, et al. IRE1 signaling is essential for ischemiainduced vascular endothelial growth factor-A expression and contributes to angiogenesis and tumor growth in vivo. B Cancer. 2007;94:S283-4.

\section{Publisher's Note}

Springer Nature remains neutral with regard to jurisdictional claims in published maps and institutional affiliations. 